\title{
HYPOXIA AND REPRODUCTIVE HEALTH Reproductive challenges at high altitude: fertility, pregnancy and neonatal well-being
}

\author{
Lorna G Moore \\ Division of Reproductive Sciences, Department of Obstetrics and Gynecology, University of Colorado Denver - \\ Anschutz Medical Campus, Aurora, Colorado, USA
}

Correspondence should be addressed to L G Moore; Email: Lorna.Moore@cuanschutz.edu

This paper forms part of a special section on Hypoxia and Reproductive Health. The guest editor for this section was Dr Jacqueline Maybin (University of Edinburgh, UK)

\begin{abstract}
High altitude offers a natural laboratory for studying the effects of chronic hypoxia on reproductive health. Counter to early accounts, fertility (the number of livebirths) appears little affected although stillbirths are more common. Birth weights are lower due to fetal growth restriction, not shortened gestation. Multigenerational (Andean or Tibetan) compared with newcomer residents appear relatively protected from pregnancy loss as well as altitude-associated fetal growth restriction, perhaps due in part to preservation of the normal rise in uterine artery blood flow. Myometrial artery vasodilator response, a key determinant of uterine blood flow, is blunted in healthy Colorado high-altitude residents, similar to what occurs in intrauterine growth restriction or preeclampsia at low altitude. The high-altitude vessels are also more sensitive to the vasodilatory actions of AMP kinase (AMPK) activation. The gene region containing PRKAA1 (coding for AMPK's alpha-1 catalytic subunit) has been acted upon by natural selection in Andeans and is related to preservation of normal blood flow and fetal growth at high altitude, suggesting one mechanism by which high-altitude adaptation may have been achieved. Preeclampsia is more common at high altitudes but unknown is whether multigenerational residents are protected relative to newcomers. Postnatal loss is diminished in Tibetans vs Han with equal access to health care, perhaps due in part to better maintained arterial $\mathrm{O}_{2}$ saturation during infancy. Finally, pregnancy and intrauterine development not only affect immediate survival but also susceptibility to the later-in-life cardiovascular disease, chronic mountain sickness.

Reproduction (2021) 161 F81-F90
\end{abstract}

\section{Introduction}

Studies at high altitude have long been of interest for the study of reproduction given the vital nature of $\mathrm{O}_{2}$ supply for the conceptus and the reduction in $\mathrm{O}_{2}$ availability at high altitudes. Reports from the Spanish Conquistadors fueled these interests with reports of the inability of imported domesticated animals or of the Spaniards themselves to reproduce, prompting successive moves of the capital from high-altitude locales to Lima at near sea level (Monge 1948). While these early accounts are subject to the uncertainties of historical reporting, they are supported by more recent observations that, even though Han populations live above $3800 \mathrm{~m}$ in the Tibet autonomous region, there were no deliveries to Han women over a 2-year period because, as we were told, the Han women descended to locations near sea level elsewhere in China to give birth Moore (Moore et al. 2001a).
Mammalian reproduction is highly complex but, as judged from the proliferation of the 19 mammalian orders following the demise of the dinosaurs approximately 65 million years ago, appears to have been highly successful. The first mammals appeared some 160 million years ago (Ji et al. 2002) and were placental (eutherian), rather than like the egg-laying prototherian (e.g. platypuses and spiny anteaters) and/or early-delivering metatherian (e.g. marsupials) mammals of today. Placental mammals today, and likely also in the past, require extensive maternal as well as fetoplacental adaptations given that the placenta, a product of the developing embryo/fetus, must negotiate between maternal and paternal genomes, and both mother and baby must protect themselves from immunologic rejection by the $50 \%$ genetically-related 'other'.

There are many important mechanisms by which the placenta as well as the ovaries, uterus, and fetus meet hypoxic challenges. Here I will address those facing 
human populations residing at high altitude. The over 140 million persons living at high altitude, conventionally defined as $>2500 \mathrm{~m}$, provide an instructive natural laboratory for understanding the problems and solutions for ensuring reproductive health under conditions of chronic hypoxia. The hypoxic stress at high altitudes is due to the obligatory fall in barometric pressure with increasing elevation, which results from the diminishing weight of the atmosphere and consequently lower partial pressure of $\mathrm{O}_{2}$ in the inspired air (Fig. 1). The 'thin air' also has the effect of increasing diurnal temperature variation, reducing humidity, and raising the level of UV radiation.

Human populations live at high altitude in four major world regions: the Rocky Mountains of North America, Andean Altiplano of South America, Himalayan Plateau of central Asia, and Ethiopian Highlands of eastern Africa. The highest year-round communities are located at $\sim 5100 \mathrm{~m}$ in southern Peru/northern Bolivia, at nearly that high in Tibet, at $3100 \mathrm{~m}$ in North America, and $2833 \mathrm{~m}$ in Ethiopia.

Genome scans using gene-chip microarrays have permitted identifying gene regions acted upon by natural selection in Andean, Himalayan and East African populations. Statistical tests are then used to detect natural selection producing, for example, increased variation, decreased variation, or increased linkage disequilibrium (i.e. the nonrandom association of alleles usually due to being situated on the same chromosome). Such statistical tests derive from the observation made nearly 50 years ago that only two of the four forces driving evolution (gene flow, or the movement of genes across populations, and natural selection) have directional effects. Since gene flow affects all loci the same way, natural selection can be measured as the heterogeneity between gene loci (Lewontin \& Krakauer 1973). With such scans and, more recently, whole genome sequencing, there has been an exponential rise in the number of studies of genetic adaptation to high altitude with over 300 publications appearing in the past 20 years.

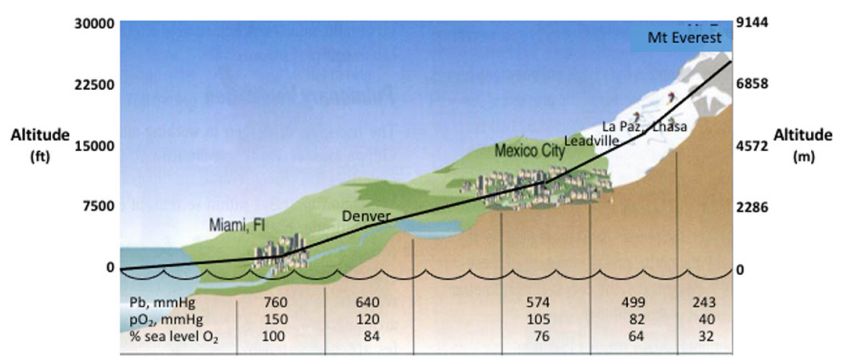

Figure 1 The hypoxia of high altitudes is due to the progressive fall in barometric pressure $(\mathrm{Pb})$ with increasing elevation. As a result, there is a concomitant fall in the partial pressure of $\mathrm{O}_{2}\left(\mathrm{pO}_{2}\right)$ in the atmosphere, which can also be expressed in terms of the percent of $\mathrm{O}_{2}$ relative to that present at sea level.
The largest number of studies has been conducted in Tibetan, Sherpa and other Himalayan populations; a considerable number in Andeans and fewer but nonetheless important ones in Ethiopian highlanders. Many genetic variants or singlenucleotidepolymorphisms (SNPs), but by no means all or even a disproportionate number, reside in the hypoxia-inducible factor (HIF) pathway (Bigham et al. 2009), which is a key mechanism by which hypoxia activates more than 100 genes. Among them are some involved in the formation of blood vessels $(V E G F, P D G F, F L T)$, red cell production (EPO), cell death (TGFA, TNF, MMP), inflammation (IL6), vasodilation or constriction (EDN, NOS, PRKAA1), glucose metabolism (IGFBP, PRKAA1) and others affecting the $\mathrm{O}_{2}$ transport system (see Beall 2014, Julian 2019, Witt \& HuertaSanchez 2019, Simonson \& Malhotra 2020 for review). With the exception of a missense mutation in the EGLN1 gene (Lorenzo et al. 2014), all the other gene regions identified thus far are not unique to high-altitude populations but rather present in different frequencies than seen in low altitude groups, indicating that natural selection has principally acted upon standing variation rather than new alleles resulting from mutations.

Residence at high altitude poses many adaptive challenges. These are summarized in Fig. 2 and, as can be seen, many cluster in the perinatal period. While much has been learned about the physiological responses to high altitude in long-resident populations (see Beall 2014, Moore 2017, Julian 2019, Simonson \& Malhotra 2020 for review), much remains to be learned as to whether and, if so, how the selected- genes influence the ability to confront these adaptive challenges. Therefore, the plan for this article is to review prior studies addressing factors directly affecting reproduction at high altitude - fertility, pregnancy, and infant survival - and the evidence for physiological adaptation during these periods in human populations.

\section{ADAPTIVE CHALLENGES OF HIGH ALTITUDE}

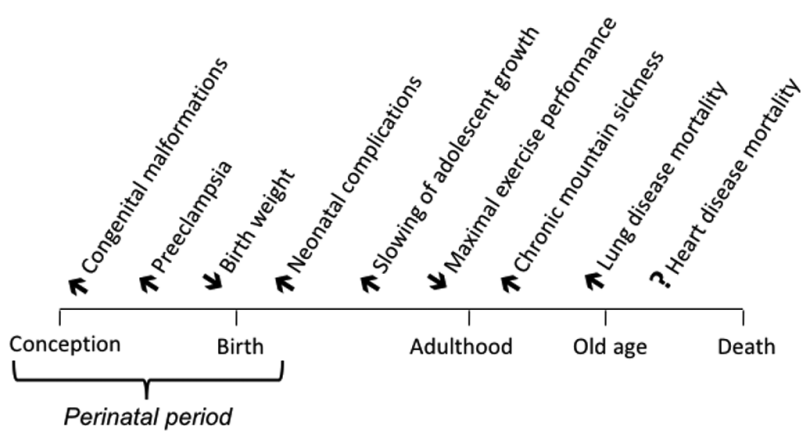

Figure 2 There are multiple challenges to reproductive success at high altitude, with several clustering in the reproductive period and early postnatal life. Such effects are likely subject to natural selection given their importance for producing offspring who survive through the completion of the reproductive period. Adapted from Moore (2017). 


\section{Fertility}

Fertility is generally defined as the ability to produce offspring, whereas fecundity refers to the processes involved in the production of viable sperm and eggs, fertilization, and carrying a pregnancy to term. The early Spaniard's descriptions of the inability of domesticated animals as well as human beings to successful reproduce made it unclear as to whether it was fecundity, fertility, or neonatal/infant survival that was impaired. The nature of mammalian reproduction makes it hard to distinguish between these processes since early pregnancy loss is difficult to detect. Here fertility is used to refer to the processes affecting the ability to produce live offspring and, more specifically, as to how residence at high altitude affects the age of menarche, menopause and the production of viable eggs and sperm.

\section{Age of menarche and menopause}

Early studies of postnatal growth in Peruvian highaltitude Quechua indicated a slow and prolonged period of adolescent growth, and an approximately 1 -year delay in the age of menarche (Frisancho 1970). While later studies indicated that poor nutrition was also a contributor to the slowed growth, a somewhat delayed age of menarche continues to be seen in Andean as well as Nepalese highland populations, but the age of menopause appears little affected (Crognier et al. 2002, Vitzthum 2013).

\section{Ovarian and testicular function}

Ovarian cycle length and the proportion of ovulatory cycles seem within the normal range in reports from the Bolivian Andes. Salivary progesterone and testosterone levels, while seasonally variable, are also within the normal range (Vitzthum 2013). Spermatogenesis is decreased following days to months of hypoxic exposure in mountaineers at extreme altitudes (Okumura et al. 2003), but to the best of our knowledge unknown for lifelong residents.

\section{Conception and pregnancy rates}

The age of first birth is somewhat delayed in rural or urban Bolivians in comparison with low altitude populations (Crognier et al. 2002). However, completed fertilities in Andean as well as Himalayan populations are either similar or greater than those of comparable low altitude groups (Vitzthum 2013). Pregnancy rates, as judged by elevated human chorionic gonadotropin levels in women seeking to conceive, also appear to be similar in high-altitude Andeans and sea-level United States of America residents (Vitzthum 2013).

\section{Pregnancy}

\section{Historical interest}

There has been a long history of studies of pregnancy at high altitude. Interest was sparked by the early fetal physiologist Joseph Barcroft, who likened the environment in which the fetus develops to 'Mt Everest in utero' (Barcroft 1946). Donald Barron and his distinguished team took this concept to the Peruvian Andes where, in sheep native to $4900 \mathrm{~m}$ in, they showed that 'despite a reduction of approximately one-half in the $\mathrm{O}_{2}$ pressure gradient between the maternal and fetal bloods, the sheep fetus at altitude lives in an internal environment in which the $\mathrm{O}_{2}$ pressure and the quantity available to it are not significantly different from that of a fetus at sea level' (Barron et al. 1964). Interestingly these sheep fetuses were not growth-restricted (Metcalfe et al. 1967).

About the same time, human high-altitude studies were being done in Colorado by Dr John Lichty, a pediatrician at the University of Colorado. He showed that in Leadville (3100 m), North America's highest city, birth weights were markedly lower than at sea level, with intermediate values being present in Denver $(1600 \mathrm{~m})$. Careful analysis of other factors influencing birth weight such as gestational age, maternal nutrition, Hispanic ethnicity, lead and other environmental contaminants, and obstetrical practices (e.g. induction of labor, frequency of Cesarean sections) led the authors to conclude that it was chronic hypoxia and not some other attribute of the high-altitude environment that was responsible (Lichty et al. 1957). Importantly this study demonstrated that the birth-weight decline was due principally to slowed fetal growth, not shortened gestation, and was thus the first to demonstrate the existence of fetal growth restriction on a population scale (Moore 2001).

\section{Pregnancy loss}

Spontaneous abortion or miscarriage is common, with about half being thought due to genetic anomalies, endocrine infections or other issues but half remains unexplained. Very low levels of $\mathrm{pO}_{2}$ are present in the uterine environment prior to the rise in uterine artery blood flow (Jauniaux et al. 2006) but whether uterine $\mathrm{pO}_{2}$ levels are affected by residence at high altitude is unknown. From 6-10 to after 10 weeks of gestation, decidual $\mathrm{PaO}_{2}$ gradually rises and is negatively correlated with the TGFbeta family proteins (i.e. inhibin, activin, VEGF, PIGF, sFLT-1 and endoglin) that are closely involved in vessel formation and placentation (Muttukrishna et al. 2008). Given the vital role of these proteins in establishing pregnancy, their dysregulation could contribute to early pregnancy loss. Consistent with such a possibility, VEGF and sFlt-1 levels were higher in women with vs without subsequent miscarriages 
and suggested to have been the result of exaggerated hypoxia and/or compromised endothelial function (Pang et al. 2013).

A large study of 22,662 consecutive births in Peru found higher rates of stillbirths at high compared to low altitudes (Gonzales et al. 2008), but another report, based on a literature review of nine studies in indigenous Andean or Himalayan residents, showed lower levels of pregnancy loss than in United States of America sea-level populations (Vitzthum 2013). Compared to high-altitude newcomers, several lines of evidence suggest that indigenous Andean as well as Himalayan residents have lower rates of pregnancy loss. Based on the difference between the numbers of pregnancies and livebirths, we found that prenatal mortality rates were one-third lower in Tibetan than Han high-altitude residents (Moore et al. 2001a). Well controlled analyses in a large series of birth records in Bolivia showed a similar degree of protection in Andean compared to European high-altitude residents (Grant et al. 2020). A Peruvian report found that birth weights were greater (more normal) in the southern than northern highland regions, which the authors attributed to the longer altitude residence of the Aymara groups in southern Peru (Gonzales 2007) but perhaps also due to the Incan domination in the north which was achieved, in part, by moving population centers to disrupt political opposition (Monge 1948).

\section{Pregnancy complications fetal growth restriction}

As noted above, the first observation on a population scale that slowed fetal growth, as well as preterm delivery, could lower birth weight came from high altitude. Since then studies have been conducted in over 7 million babies on three continents - North America, South America and Asia - that demonstrate an approximately $100 \mathrm{~g}$ birth-weight reduction for every 1000 m elevation gain (Jensen \& Moore 1997, Mortola et al. 2000, Hartinger et al. 2006, Bailey et al. 2020). While multiple factors can reduce fetal growth and most of these studies had only birth weights and gestational age estimates available (and not, e.g., fetal biometry showing progressive reductions in estimated fetal weight or Doppler indices of brain sparing), the consistency among these reports implicate a slowing of fetal growth as the primary cause.

The effect of high-altitude residence on fetal growth is strongly population dependent. Across a sea level to $3600 \mathrm{~m}$ altitude gradient, the greatest reductions are seen in North America (352 g), intermediate declines in South America (270 and 282 in Peru and Bolivia respectively), and the least effect in Tibetans (72 g) (Niermeyer 2001). This order approximates the differing durations of human occupation; paleontological or archeological evidence shows that there has been human occupation of the Tibetan Plateau for as long as 25,000 years and of the Andean altiplano for $\sim 14,000$ years. There are no cities in Europe at an elevation above $2500 \mathrm{~m}$ so Europeanderived population residence at high altitude is limited to 400 years in South America and only 150 years in North America (Native American residents of high altitude were not considered since their occupation of high-altitude regions in the Rocky Mountains was seasonal). The duration of human residence at high altitudes in Ethiopia is unclear and, to our knowledge, no birth weight studies in relation to altitude have been conducted there.

To better assess the influence of duration of highaltitude residence on fetal growth, we considered those studies in which samples were collected by the same investigative team in residents living at $\sim 3600 \mathrm{~m}$ (conveniently, the altitude at which both La Paz, Bolivia and Lhasa, Tibet Autonomous Region, China are located) and sea level, and for which ancestry was assessed by self-report, surnames, or gene markers. Shown in Fig. 3 is the mean birth weights for the 305,935 babies born to these Andean, Tibetan, European or Han women. Of interest, the average birth-weight reduction in the Andeans and Tibetans is similar, averaging $167 \mathrm{~g}$, and approximately half that seen in Europeans or Han. In a follow-up study in Bolivia, we considered whether one or several generations of high-altitude residence conferred protection. Using gene markers to confirm population ancestry, lifelong or up to four generations of high-altitude residence conferred little benefit as the birth weights of babies born to such women were similar to those of newcomers, suggesting that genetic rather than developmental factors were responsible (Julian et al. 2011).

The rise in uterine artery blood flow during pregnancy exerts an important influence on fetal growth (Palmer et al. 1992, Konje et al. 2003). In a series of reports, we have shown that there is less pregnancy-associated rise in uterine artery blood flow at high compared to low altitude, which is due principally to a lesser increase in uterine artery diameter (Zamudio et al. 1995, Julian et al. 2008, 2009).
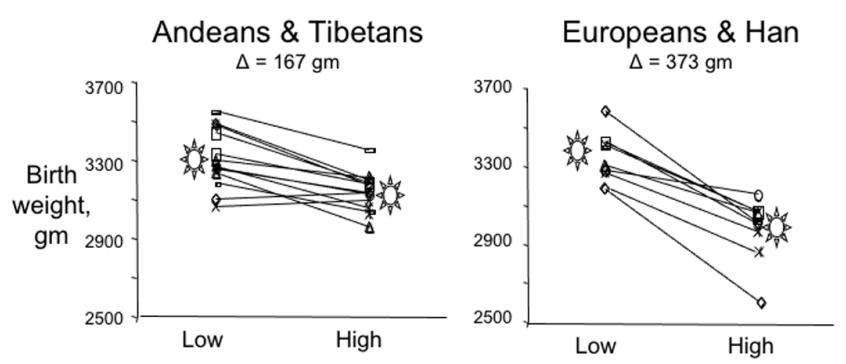

Figure 3 Mean birth weights are shown for infants born to multigenerational (Andean or Tibetan) mothers or shorter-term (European or Han 'Chinese') women who reside either at high $(\sim 3600 \mathrm{~m})$ or low altitude ( sea level). Represented are birth weights from a total of 305,935 infants and 15 studies. Adapted from Niermeyer and Moore (2015). 
The importance of uterine artery diameter is often overlooked in studies of pregnancy complications where, often, only uterine artery resistance indices are measured. Such indices are derived from systolic and end-diastolic flow velocities and while easily obtained, neither measure volumetric blood flow nor vascular resistance since, by definition, resistance is blood pressure divided by flow. Trophoblast-induced remodeling of the end spiral arterioles into dilated, flaccid vessels does indeed reduce uteroplacental vascular resistance, but changes in the more upstream vessels are also important contributors for several reasons (Clark et al. 2018). First, the spiral artery remodeling effectively moves the primary site of vascular resistance upstream to the myometrial arteries, which undergo remodeling and vasoreactivity that are primarily due to maternal factors, not simply trophoblast invasion. Secondly, alterations in the growth, remodeling and/or vasoreactivity of the uterine and other upstream arteries begin prior to the completion of trophoblast invasion, and are responsible for the major portion of the uterine artery blood flow rise up to week 16 (Dickey \& Hower 1995, Osol \& Moore 2014).

Given the importance of myometrial arteries for the determination of uteroplacental vascular resistance, $\mathrm{Dr}$ Ramón Lorca from our group has performed myometrial artery vasoreactivity studies in vessels isolated from biopsies obtained at unlabored cesarean section from Colorado low- and high-altitude residents. Similar to what has been reported from IUGR or preeclamptic pregnancies at sea level (Cockell \& Poston 1997, Kublickiene et al. 1997, Ong et al. 2003, Kublickiene et al. 2000, Luksha et al. 2010), myometrial artery vasodilator response was blunted in the vessels from the high- $(2902 \mathrm{~m})$ compared to the low- $(1600 \mathrm{~m})$ altitude women (Lorca et al. 2019). The blunted response was due to impaired nitric oxide signaling, similar to what been seen in high-altitude exposed guinea pigs or rats (White et al. 2000, Aljunaidy et al. 2016). Greater myogenic tone in resistance vessels in the uterine circulation of pregnant sheep exposed to high altitude has also been reported, and attributed to less potassiumchannel vasodilation (Hu et al. 2012). Other factors may also be involved since, for example, pregnant Andeans vs European high-altitude residents had higher activity levels for the anti-oxidants, catalase and superoxide dismutase, and possibly therefore greater protection from oxidative stress (Julian et al. 2012). Thus, existing data provide compelling evidence that chronic hypoxia can interfere with the normal maternal, uterine vasodilator responses to pregnancy so as to reduce uteroplacental blood flow and thereby contributes to the reduction in fetal growth.

To determine the genetic factors involved in Andean protection from altitude-associated fetal growth restriction, we conducted genome scans to identify gene regions showing evidence of having been acted upon by natural selection (Bigham et al. 2009), and then carried out association studies to identify those related to protection from altitude-associated reductions in birth weight and uterine artery blood flow. We found that gene regions containing PRKAA1, which codes for the alpha- 1 catalytic subunit of AMP kinase (AMPK) and EDNRA, which controls the expression of the vascular smooth muscle cell endothelin receptor A, were related to heavier (more normal) birth weights at high altitude. However, only the selected-for PRKAA1 genotype was positively related to both birth weight and uterine artery diameter at high altitude. Suggesting a functional link, the PRKAA1 SNPs were also associated with the expression patterns of mTOR pathway genes implicated in fetal growth restriction (Bigham et al. 2014).

Currently, we are examining the effects of AMPK activation in vitro in women and, in mice, in vivo. Addition of the AMPK agonist, A769662, has potent vasodilator effects in isolated mouse main uterine arteries and human myometrial arteries; these are partially due to stimulation of nitric oxide production but largely to vascular smooth muscle actions (Skeffington et al. 2016, Lane et al. 2019, Lorca et al. 2019). Mice treated at mid-gestation with the AMPK activator AICAR and then exposed to hypoxia until term have increased uterine artery diameters, greater uterine artery blood flow (either absolutely or expressed as a percent of cardiac output), and only half the altitudeassociated reduction in fetal growth compared with their hypoxia-exposed, vehicle-treated counterparts (Lane et al. 2020). Further, we have recently published studies showing that AMPK activation not only dilates myometrial arteries but that its effects are greater in vessels from appropriate for gestational age (AGA) vs IUGR pregnancies (Lorca et al. 2020). While much remains to be learned, given that drugs such as metformin activate AMPK and have been safely used in pregnancy, such studies offer the possibility of yielding new therapies for treating or preventing pregnancy disorders characterized by uteroplacental ischemia and hypoxia.

Other oxygen-transport related variables have also been associated with preserved fetal growth or reproductive outcomes. At high altitudes in Colorado, Peru and Tibet, greater pregnancy-associated increases in hypoxic ventilatory sensitivity, ventilation, and arterial oxygenation are positively related to infant birth weight (Moore et al. 1982, 1986, 2001b). Ethnically Tibetan women living at high altitudes in Nepal with lower hemoglobin levels and higher $\mathrm{SaO}_{2}$ also had better pregnancy outcomes (Cho et al. 2017). Consistent with this, high $(>14.5 \mathrm{~g} / \mathrm{dL})$ as well as very low $(<7 \mathrm{~g} / \mathrm{dL})$ hemoglobin levels are associated with poor pregnancy outcomes at high or low altitude (Gonzales et al. 2009), likely due to better placental perfusion of lower viscosity blood. 


\section{Pregnancy complications preeclampsia}

Preeclampsia occurs in $\sim 2-8 \%$ of pregnancies at low altitude and is part of a spectrum of hypertensive disorders of pregnancy (HDP) that includes gestational hypertension, preeclampsia, HELLP (hemolysis, elevated liver enzymes, and low platelets) syndrome, and eclampsia. It has been attributed to impaired trophoblast invasion and resultant incomplete maternal spiral artery remodeling when detected early $(<34$ weeks), and to maternal factors when manifesting later (Staff 2019). While clearly the placenta plays a major role, as HDP resolve within days of birth and removal of the placenta, other factors are also likely important for several reasons. Incomplete spiral artery as well as neighboring myometrial artery remodeling is not specific to preeclampsia, as it also occurs in IUGR (Lyall et al. 2013). The systemic nature of HDP is associated with increased markers of oxidative stress and loss of VEGF activity due to elevated sFlt-1 and/or reduced PIGF production, increased soluble endoglin, reduced nitric oxide and other vasodilator gasotransmitters $\left(\mathrm{CO}, \mathrm{H}_{2} \mathrm{~S}\right)$, elevated endothelin-1, increased activin $A$ and inhibin A, and alterations in various miRNA (Ahmed et al. 2017, Phipps et al. 2019). Changes on the maternal side of the uteroplacental circulation also play crucial roles (Than et al. 2018, Ridder et al. 2019). For example, transcriptomic analyses in a landmark study employing chorionic villous sampling during the first trimester showed that the pathways affected in women who later developed preeclampsia were not those typically associated with hypoxia or oxidative stress, but rather with defective pre-decidualization or decidualization (Founds et al. 2009, Conrad et al. 2017), pointing to crucial roles for the 'soil' and not just the 'seed'.

Preeclampsia and the other HDP are more common at high than low altitudes in Colorado and Bolivia (Palmer et al. 1999, Keyes et al. 2003, Bailey et al. 2020) but unknown is whether this is also true in Tibet or Ethiopia. In a recent comprehensive study of all births to Colorado residents from 2007 to 2016 ( $n=652,028)$, we showed that each disorder separately or all combined was 33\% more common at altitudes above than below $2500 \mathrm{~m}$ (Bailey et al. 2020). The increased incidence of HDP at high altitudes is an important contributor to the altitudeassociated reduction in birth weight, accounting for half the birth-weight fall in Bolivia (Keyes et al. 2003).

While, as noted above, multigenerational highaltitude residents are relatively protected from fetal growth restriction, it is not clear whether such protection extends to preeclampsia and other HDP but suggesting that it may, lower rates of preeclampsia/gestational hypertension have been reported for Tibetan than Han residents of Lhasa $(3658 \mathrm{~m})$ in the Tibet Autonomous Region of China (Miller et al. 2008). Current data are insufficient to address whether Andeans are also protected. Suggesting that they might be is that pregnant
Andean compared with European women have lower sFlt-1 levels and sFlt-1/PLGF ratios (Davila et al. 2010), both of which are protective against preeclampsia (Chaiworapongsa et al. 2014). Andeans may also benefit from higher levels of anti-oxidants (Julian et al. 2012), progesterone, estrone, 17-beta estradiol and estriol (Charles et al. 2014). Cortisol levels are lower as well, with lower cortisol and higher estriol being associated with greater uterine artery diameter and blood flows in Andeans. But nonetheless preeclampsia and other HDP are frequent complications of pregnancy in La Paz, Bolivia and, in early-onset cases, are accompanied by elevated uterine artery resistance indices and reduced volumetric blood flow (Browne et al. 2011).

Preeclampsia is a major cause of maternal mortality at high altitude, being among the leading causes in Bolivia which has the second highest rate of maternal mortality in South America (Toledo-Jaldin et al. 2019). Preeclampsia is also associated with increased infant mortality and risk of cardiovascular and other diseases for both mother and offspring mortality later in life (Bellamy et al. 2007). Greater attention is needed for improving its diagnosis and treatment in all locales, but especially in the predominantly low- to middle-income countries where $99 \%$ of preeclampsia deaths occur (Duley 1992). The study of preeclampsia continues to be challenging given that (1) while at least some of its signs or symptoms can be invoked in animal models, it is a uniquely human disease; (2) longitudinal studies of its time course are difficult at a $2-8 \%$ incidence rate and (3) evaluation of predictive biomarkers or potential therapies is limited by the large number that are needed to treat when the incidence is low (i.e. 500 at a $2 \%$ incidence vs 56 at an 18\% incidence (Askie et al. 2007)). Thus, studies at high altitude offer an important setting for potentially furthering our knowledge of responsible mechanisms and developing new therapies (Bailey et al. 2020).

\section{Infant survival}

The greatest predictors of infant mortality are birth weight and gestational age. Hence clearly the reduction in birth weights seen at high altitude poses a risk for infant survival. While gestational age is little affected in healthy pregnancy, it is often reduced in preeclampsia as the result of spontaneous preterm delivery or clinical decision to deliver if maternal and/or infant health is threatened.

Given the lower average birth weights at high altitudes, it would be expected that neonatal and, by extension, infant mortality would be increased. This is supported by older studies in Colorado in which mortality rates at high altitudes were higher than those observed at lower elevations (McCullough \& Reeves 1977) but mortality rates at high altitudes in the state no longer differ by altitude (Unger et al. 1988). Bolivia's infant mortality 
rate is high (35.3/1000 livebirths) and twice the South American average. While the reporting of infant deaths is incomplete and multiple socioeconomic, healthcare and other factors complicate their interpretation, the limited data available indicate that infant mortality rates increase with elevation in Bolivia (Giussani 2002). Mortality estimates for the Tibet Autonomous Region, the high-altitude regions of the adjacent Qinghai Province in China, or the high compared to low altitude regions Peru or Ethiopia are not, to our knowledge, available.

There is some, albeit limited, evidence that postnatal mortality may be lower in Tibetan than Han residents of high altitude under conditions of comparable health care. We collected birth weights and prenatal as well as postnatal mortality data in 495 consecutive deliveries over an 18-month period at eight hospitals or clinics serving predominantly rural or small communities at altitudes from 2700 to $4700 \mathrm{~m}$ in Tibet (Moore et al. 2001a). The women delivering during this period had a total of 863 prior pregnancies and 734 babies born previously. From these data we calculated postnatal mortality but, in the absence of data as to when deaths had occurred, were not able to provide age-specific estimates. Postnatal mortality increased with elevation in Tibetans. While sample sizes were too small to assess altitudinal effects in Han, postnatal mortality across all altitudes was nearly one-third lower in Tibetans than Han (120 vs 320 deaths per 1000 livebirths).

Compared to the $96-98 \%$ value seen at sea level, $\mathrm{SaO}_{2}$ is lower in neonates and infants born at high altitude; at $1600 \mathrm{~m}$ in Denver, values are 92-94\% during the first 3 months of age, and 81 to $91 \%$ during the first 4 months of life in Leadville, CO (3100 m) (Niermeyer et al. 1993). In Lhasa (3658 m), $\mathrm{SaO}_{2}$ values in babies born to healthy mothers declined from birth to 4 months of age, with values being markedly and consistently higher in Tibetan than Han infants. Specifically, $\mathrm{SaO}_{2}$ ranged from 94 to $88 \%$ at birth and $88-86 \%$ at 4 months of age in the Tibetans vs $92-80 \%$ at birth to $85-76 \%$ at 4 months of age in the Han babies for the awake or quiet sleep states, respectively (Niermeyer et al. 1995). Limited $\mathrm{SaO}_{2}$ data in 15 healthy Andean babies born in La Paz, Bolivia (3600 m) also showed an age-related decline. Across all study times, values were higher in Tibetan than Andean babies in all but the feeding state; Andean values were higher than those seen in the Han babies while feeding and also tended to be higher after 1 month of age in the awake, active or quiet sleep states (Niermeyer et al. 2015).

Pulmonary arterial pressure (Ppa) normally undergoes a rapid fall in the first days after birth at low altitude, but this decline can be prolonged or absent in babies born at high altitudes without supplemental $\mathrm{O}_{2}$ administration. Elevated Ppa and an increased prevalence of patent ductus arteriosus have been described at high altitudes in Andean and Himalayan regions (Sime et al. 1963). Accurate prevalence data with which to compare indigenous and newcomer groups are not available, although there is some suggestion that such disorders may be more common in Han than Tibetan infants (Sui et al. 1988), possibly due to their better-sustained $\mathrm{SaO}_{2}$ during early infancy.

With the increasing recognition of the importance of impaired intrauterine or early post natal development for susceptibility to cardiovascular and other diseases later in life (Barker 1999), it is of interest that middle- to olderaged men with the condition known as chronic mountain sickness (CMS) more often weighed less at birth than their equal-aged counterparts (Moore et al. 2007). CMS is a syndrome characterized by hemoglobin levels more than 3 standard deviations above the mean, hypoxemia especially during sleep and often pulmonary hypertension but without other underlying cardiopulmonary disease. It occurs in $8-10 \%$ of lifelong or multigenerational highaltitude resident males in South America but only rarely in Tibetans and has not been described in Ethiopia. CMS appears to have a hereditary component (Zhou et al. 2013), with several candidate genes being identified (Gazal et al. 2019). In 18-25 year old men with a preclinical form of CMS, in which hemoglobin levels are elevated but only 2 standard deviations above the mean and otherwise healthy, Dr Colleen Julian together with her Bolivian colleagues showed that those with preclinical CMS were four times more often hypoxic during perinatal life, three times more often born to preeclamptic mothers (Julian et al. 2015), had higher levels of the oxidative stress marker 8-iso-PGF2 2 alpha, and lower $\mathrm{SaO}_{2}$ during sleep than similarly aged controls (Julian et al. 2013).

\section{Future perspectives}

Studies at high altitude have proven instructive for increasing our understanding of the effects of hypoxia on reproduction and of the processes of human adaptation. Given the increasing recognition of the importance of early-life events for lifelong health, they hold promise for improving our understanding of health determinants later-in-life as well. Since most of the world's 140 million high-altitude residents live in LMIC, increased research on both the mechanisms responsible for pregnancy, fetal and other reproductive disorders in developing countries as well as for improving the treatments or preventive therapies for such conditions are warranted.

\section{Declaration of interest}

The author declares that there is no conflict of interest that could be perceived as prejudicing the impartiality of this review.

\section{Funding}

Apart from funding for the support of the research in which the author was involved and is cited here, the writing of this article did not receive any specific grant from any funding agency. 


\section{Author contribution statement}

L G M conceived the review and wrote the paper.

\section{Acknowledgement}

Appreciation is extended to the many human subjects who agreed to participate in the studies cited in this review, as well as to the many persons who helped with study conduct.

\section{References}

Ahmed A, Rezai H \& Broadway-Stringer S 2017 Evidence-based revised view of the pathophysiology of preeclampsia. Advances in Experimental Medicine and Biology 956 355-374. (https://doi. org/10.1007/5584_2016_168)

Aljunaidy MM, Morton JS, Cooke CL \& Davidge ST 2016 Maternal vascular responses to hypoxia in a rat model of intrauterine growth restriction. American Journal of Physiology: Regulatory, Integrative and Comparative Physiology 311 R1068-R1075. (https://doi.org/10.1152/ ajpregu.00119.2016)

Askie LM, Duley L, Henderson-Smart DJ, Stewart LA \& PARIS Collaborative Group 2007 Antiplatelet agents for prevention of pre-eclampsia: a metaanalysis of individual patient data. Lancet 369 1791-1798. (https://doi. org/10.1016/S0140-6736(07)60712-0)

Bailey BA, Euser AG, Bol KA, Julian CG.\& Moore LG 2020 High-altitude residence alters blood-pressure course and increases hypertensive disorders of pregnancy. Journal of Maternal-Fetal and Neonatal Medicine 30 1-8. (https://doi.org/10.1080/14767058.2020.1745181)

Barcroft J 1946 Researches in Perinatal Life. Oxford, UK: Blackwell Publishing.

Barker DJP 1999 Fetal origins of cardiovascular disease. Annals of Medicine 31 (Supplement 1) 3-6. (https://doi.org/10.1080/07853890.1 999.11904392)

Barron DH, Metcalfe J, Meschia G, Huckabee W, Hellegers A \& Prystowsky H 1964 Adaptations of pregnant ewes and their fetuses to high altitude. In The Physiological Effects of High Altitude. Ed WH Weihe. New York: Macmillan.

Beall CM 2014 Adaptation to high altitude: phenotypes and genotypes. Annual Review of Anthropology 43 251-272. (https://doi.org/10.1146/ annurev-anthro-102313-030000)

Bellamy L, Casas JP, Hingorani AD \& Williams DJ 2007 Pre-eclampsia and risk of cardiovascular disease and cancer in later life: systematic review and meta-analysis. BMJ 335 974. (https://doi.org/10.1136/ bmj.39335.385301.BE)

Bigham AW, Mao X, Mei R, Brutsaert T, Wilson MJ, Julian CG, Parra EJ Akey JM, Moore LG \& Shriver MD 2009 Identifying positive selection candidate loci for high-altitude adaptation in Andean populations. Human Genomics 4 79-90. (https://doi.org/10.1186/1479-7364-4-2-79)

Bigham AW, Julian CG, Wilson MJ, Vargas E, Browne VA, Shriver MD \& Moore LG 2014 Maternal PRKAA1 and EDNRA genotypes are associated with birth weight, and PRKAA1 with uterine artery diameter and metabolic homeostasis at high altitude. Physiological Genomics 46 687-697. (https://doi.org/10.1152/physiolgenomics.00063.2014)

Browne VA, Toledo-Jaldin L, Davila RD, Lopez LP, Yamashiro H, CioffiRagan D, Julian CG, Wilson MJ, Bigham AW, Shriver MD et al. 2011 High-end arteriolar resistance limits uterine artery blood flow and restricts fetal growth in preeclampsia and gestational hypertension at high altitude. American Journal of Physiology: Regulatory, Integrative and Comparative Physiology 300 R1221-R1229. (https://doi.org/10.1152/ ajpregu.91046.2008)

Chaiworapongsa T, Chaemsaithong P, Korzeniewski SJ, Yeo L. \& Romero R 2014 Pre-eclampsia part 2: prediction, prevention and management. Nature Reviews: Nephrology 10 531-540. (https://doi.org/10.1038/ nrneph.2014.103)

Charles SM, Julian CG, Vargas E \& Moore LG 2014 Higher estrogen levels during pregnancy in Andean than European residents of high altitude suggest differences in aromatase activity. Journal of Clinical Endocrinology and Metabolism 99 2908-2916. (https://doi.org/10.1210/ jc.2013-4102)
Cho JI, Basnyat B, Jeong C, Di Rienzo A, Childs G, Craig SR, Sun J \& Beall CM 2017 Ethnically Tibetan women in Nepal with low hemoglobin concentration have better reproductive outcomes. Evolution, Medicine, and Public Health 2017 82-96. (https://doi.org/10.1093/emph/eox008)

Clark AR, James JL, Stevenson GN \& Collins SL 2018 Understanding abnormal uterine artery Doppler waveforms: a novel computational model to explore potential causes within the utero-placental vasculature. Placenta 66 74-81. (https://doi.org/10.1016/j.placenta.2018.05.001)

Cockell AP \& Poston L 1997 Flow-mediated vasodilatation is enhanced in normal pregnancy but reduced in preeclampsia. Hypertension 30 247-251. (https://doi.org/10.1161/01.hyp.30.2.247)

Conrad KP, Rabaglino MB.\& Post Uiterweer ED 2017 Emerging role for dysregulated decidualization in the genesis of preeclampsia. Placenta $\mathbf{6 0}$ 119-129. (https://doi.org/10.1016/j.placenta.2017.06.005)

Crognier E, Villena M \& Vargas E 2002 Reproduction in high altitude Aymara: physiological stress and fertility planning? Journal of Biosocial Science 34 463-473. (https://doi.org/10.1017/ s0021932002004637)

Davila RD, Julian CG, Wilson MJ, Browne VA, Rodriguez C, Bigham AW, Shriver MD, Vargas E \& Moore LG 2010 Do anti-angiogenic or angiogenic factors contribute to the protection of birth weight at high altitude afforded by Andean ancestry? Reproductive Sciences 17 861-870. (https://doi.org/10.1177/1933719110372418)

Dickey RP \& Hower JF 1995 Ultrasonographic features of uterine blood flow during the first 16 weeks of pregnancy. Human Reproduction 10 2448-2452. (https://doi.org/10.1093/oxfordjournals.humrep.a136317)

Duley L 1992 Maternal mortality associated with hypertensive disorders of pregnancy in Africa, Asia, Latin America and the Caribbean. British Journal of Obstetrics and Gynaecology 99 547-553. (https://doi. org/10.1111/j.1471-0528.1992.tb13818.x)

Founds SA, Conley YP, Lyons-Weiler JF, Jeyabalan A, Hogge WA \& Conrad KP 2009 Altered global gene expression in first trimester placentas of women destined to develop preeclampsia. Placenta 30 15-24. (https://doi.org/10.1016/j.placenta.2008.09.015)

Frisancho AR 1970 Developmental responses to high altitude hypoxia. American Journal of Physical Anthropology 32 401-407. (https://doi. org/10.1002/ajpa.1330320310)

Gazal S, Espinoza JR, Austerlitz F, Marchant D, Macarlupu JL, Rodriguez J, Ju-Preciado $H$, Rivera-Chira $M$, Hermine $O$, LeonVelarde F et al. 2019 The genetic architecture of chronic mountain sickness in Peru. Frontiers in Genetics 10 690. (https://doi.org/10.3389/ fgene.2019.00690)

Giussani D 2002 High altitude and rural living are associated with increased infant mortality in Bolivia. Journal of the Society for Gynecologic Investigation 9 (Supplement) 292A.

Gonzales GF 2007 Peruvian contributions to the study on human reproduction at high altitude: from the chronicles of the Spanish conquest to the present. Respiratory Physiology and Neurobiology 158 172-179. (https://doi.org/10.1016/j.resp.2007.03.015)

Gonzales GF, Tapia V \& Carrillo CE 2008 Stillbirth rates in Peruvian populations at high altitude. International Journal of Gynaecology and Obstetrics 100 221-227. (https://doi.org/10.1016/j.ijgo.2007.08.009)

Gonzales GF, Steenland K \& Tapia V 2009 Maternal hemoglobin level and fetal outcome at low and high altitudes. American Journal of Physiology: Regulatory, Integrative and Comparative Physiology 297 R1477-R1485. (https://doi.org/10.1152/ajpregu.00275.2009)

Grant I, Soria R, Julian CG, Vargas E, Moore LG, Aiken CE \& Giussani DA 2020 Parental ancestry and risk of early pregnancy loss at high altitude. FASEB Journal In press. (https://doi.org/10.1096/fj.202001257R)

Hartinger S, Tapia V, Carrillo C, Bejarano L \& Gonzales GF 2006 Birth weight at high altitudes in Peru. International Journal of Gynaecology and Obstetrics 93 275-281. (https://doi.org/10.1016/j.ijgo.2006.02.023)

Hu XQ, Xiao D, Zhu R, Huang X, Yang S, Wilson SM \& Zhang L 2012 Chronic hypoxia suppresses pregnancy-induced upregulation of large-conductance Ca2+-activated $\mathrm{K}+$ channel activity in uterine arteries. Hypertension 60 214-222. (https://doi.org/10.1161/ HYPERTENSIONAHA.112.196097)

Jauniaux E, Poston L \& Burton GJ 2006 Placental-related diseases of pregnancy: involvement of oxidative stress and implications in human evolution. Human Reproduction Update 12 747-755. (https://doi. org/10.1093/humupd/dml016)

Jensen GM \& Moore LG 1997 The effect of high altitude and other risk factors on birthweight: independent or interactive effects? American 
Journal of Public Health 87 1003-1007. (https://doi.org/10.2105/ ajph.87.6.1003)

Ji Q, Luo ZX, Yuan CX, Wible JR, Zhang JP \& Georgi JA 2002 The earliest known eutherian mammal. Nature 416 816-822. (https://doi. org/10.1038/416816a)

Julian CG 2019 An aptitude for altitude: are epigenomic processes involved? Frontiers in Physiology 10 1397. (https://doi.org/10.3389/ fphys.2019.01397)

Julian CG, Galan HL, Wilson MJ, Desilva W, Cioffi-Ragan D, Schwartz J \& Moore LG 2008 Lower uterine artery blood flow and higher endothelin relative to nitric oxide metabolite levels are associated with reductions in birth weight at high altitude. American Journal of Physiology: Regulatory, Integrative and Comparative Physiology 295 R906-R915. (https://doi. org/10.1152/ajpregu.00164.2008)

Julian CG, Wilson MJ, Lopez M, Yamashiro H, Tellez W, Rodriguez A, Bigham AW, Shriver MD, Rodriguez C, Vargas E et al. 2009 Augmented uterine artery blood flow and oxygen delivery protect Andeans from altitude-associated reductions in fetal growth. American Journal of Physiology: Regulatory, Integrative and Comparative Physiology 296 R1564-R1575. (https://doi.org/10.1152/ajpregu.90945.2008)

Julian CG, Hageman JL, Wilson MJ, Vargas E \& Moore LG 2011 Lowland origin women raised at high altitude are not protected against lower uteroplacental $\mathrm{O} 2$ delivery during pregnancy or reduced birth weight. American Journal of Human Biology 23 509-516. (https://doi. org/10.1002/ajhb.21167)

Julian CG, Vargas E, Browne VA, Wilson MJ, Bigham AW, Rodriguez C, Mccord JM \& Moore LG 2012 Potential role for elevated maternal enzymatic antioxidant status in Andean protection against altitude-associated SGA. Journal of Maternal-Fetal and Neonatal Medicine 25 1233-1240. (https://doi.org/10.3109/14767058 .2011.636102)

Julian CG, Vargas E, Gonzales M, Davila RD, Ladenburger A, Reardon L, Schoo C, Powers RW, Lee-Chiong T \& Moore LG 2013 Sleep-disordered breathing and oxidative stress in preclinical chronic mountain sickness (excessive erythrocytosis). Respiratory Physiology and Neurobiology 186 188-196. (https://doi.org/10.1016/j.resp.2013.01.016)

Julian CG, Gonzales M, Rodriguez A, Bellido D, Salmo CS, Ladenburger A, Reardon L, Vargas E \& Moore LG 2015 Perinatal hypoxia increases susceptibility to high-altitude polycythemia and attendant pulmonary vascular dysfunction. American Journal of Physiology: Heart and Circulatory Physiology 309 H565-H573. (https://doi.org/10.1152/ ajpheart.00296.2015)

Keyes LE, Armaza JF, Niermeyer S, Vargas E, Young DA \& Moore LG 2003 Intrauterine growth restriction, preeclampsia, and intrauterine mortality at high altitude in Bolivia. Pediatric Research 54 20-25. (https://doi. org/10.1203/01.PDR.0000069846.64389.DC)

Konje JC, Howarth ES, Kaufmann P. \& Taylor DJ 2003 Longitudinal quantification of uterine artery blood volume flow changes during gestation in pregnancies complicated by intrauterine growth restriction. BJOG 110 301-305. (https://doi.org/10.1046/j.1471-0528.2003.t01-102163.x)

Kublickiene KR, Cockell AP, Nisell H \& Poston L 1997 Role of nitric oxide in the regulation of vascular tone in pressurized and perfused resistance myometrial arteries from term pregnant women. American Journal of Obstetrics and Gynecology 177 1263-1269. (https://doi.org/10.1016/ s0002-9378(97)70048-6)

Kublickiene KR, Lindblom B, Kruger K \& Nisell H 2000 Preeclampsia: evidence for impaired shear stress-mediated nitric oxide release in uterine circulation. American Journal of Obstetrics and Gynecology 183 160-166. (https://doi.org/10.1067/mob.2000.105820)

Lane SL, Doyle AS, Bales ES, Lorca RA, Julian CG \& Moore LG 2019 Increased uterine artery blood flow in hypoxic murine pregnancy is not sufficient to prevent fetal growth restriction. Biology of Reproduction 102 660-670. (https://doi.org/10.1093/biolre/ioz208)

Lane SL, Houck JA, Doyle AS, Bales ES, Lorca RA, Julian CG \& Moore LG 2020 AMP-activated protein kinase activator AICAR attenuates hypoxia-induced fetal growth restriction in mice by improving uterine artery blood flow. Journal of Physiology 598 4093-4105. (https://doi. org/10.1113//P279341)

Lewontin RC \& Krakauer J 1973 Distribution of gene frequency as a test of the theory of the selective neutrality of polymorphisms. Cenetics $\mathbf{7 4}$ 175-195.
Lichty JA, Ting RY, Brun PD \& Dyar E 1957 Studies of babies born at high altitudes. I. Relation of altitude to birth weight. A.M.A. Journal of Diseases of Children 93 666-669. (https://doi.org/10.1001/ archpedi.1957.02060040668009)

Lorca R, Coates S, Bales E, Nsier H, Yi H, Julian C \& Moore L 2019 Chronic hypoxia reduces $\mathrm{NO}$-dependent myometrial artery vasodilator response during pregnancy. Hypertension 73 1319-1326.

Lorca RA, Matarrazo CJ, Bales ES, Houck JA, Orlicky DJ, Julian CG, Euser AG \& Moore LG 2020 AMPK activation in pregnant human myometrial arteries from high-altitude and intrauterine growth-restricted pregnancies. American Journal of Physiology: Heart and Circulatory Physiology 319 H203-H212. (https://doi.org/10.1152/ajpheart.00644.2019)

Lorenzo FR, Huff C, Myllymäki M, Olenchock B, Swierczek S, Tashi T, Gordeuk V, Wuren T, Ri-Li G, McClain DA et al. 2014 A genetic mechanism for Tibetan high-altitude adaptation. Nature Genetics $\mathbf{4 6}$ 951-956. (https://doi.org/10.1038/ng.3067)

Luksha L, Luksha N, Kublickas M, Nisell H \& Kublickiene K 2010 Diverse mechanisms of endothelium-derived hyperpolarizing factor-mediated dilatation in small myometrial arteries in normal human pregnancy and preeclampsia. Biology of Reproduction 83 728-735. (https://doi. org/10.1095/biolreprod.110.084426)

Lyall F, Robson SC \& Bulmer JN 2013 Spiral artery remodeling and trophoblast invasion in preeclampsia and fetal growth restriction: relationship to clinical outcome. Hypertension 62 1046-1054. (https:// doi.org/10.1161/HYPERTENSIONAHA.113.01892)

McCullough RE \& Reeves JT 1977 Fetal growth retardation and increased infant mortality at high altitide. Archives of Environmental Health 32 36-39. (https://doi.org/10.1080/00039896.1977.10667251)

Metcalfe J, Bartel H. \& Moll W 1967 Gas exchange in the pregnant uterus. Physiological Reviews 47 782-838. (https://doi.org/10.1152/ physrev.1967.47.4.782)

Miller S, Tudor C, Thorsten V, Wright L. \& Varner M 2008 Comparison of maternal and newborn outcomes of Tibetan and Han Chinese delivering in Lhasa, Tibet. Journal of Obstetrics and Gynaecology Research 34 986-993. (https://doi.org/10.1111/j.1447-0756.2008.00804.x)

Monge MC 1948 Acclimatization in the Andes: Historical Confirmations of 'Climatic Aggression' in the Development of Andean Man. Baltimore, MD: Johns Hopkins University Press.

Moore LG 2001 Human genetic adaptation to high altitude. High Altitude Medicine and Biology 2 257-279. (https://doi. org/10.1089/152702901750265341)

Moore LG 2017 Measuring high-altitude adaptation. Journal of Applied Physiology 123 1371-1385. (https://doi.org/10.1152/ japplphysiol.00321.2017)

Moore LG, Rounds SS, Jahnigen D, Grover RF \& Reeves JT 1982 Infant birth weight is related to maternal arterial oxygenation at high altitude. Journal of Applied Physiology: Respiratory, Environmental and Exercise Physiology 52 695-699. (https://doi.org/10.1152/jappl.1982.52.3.695)

Moore LG, Brodeur P, Chumbe O, D'Brot J, Hofmeister S \& Monge C 1986 Maternal hypoxic ventilatory response, ventilation, and infant birth weight at 4,300 m. Journal of Applied Physiology 60 1401-1406. (https:// doi.org/10.1152/jappl.1986.60.4.1401)

Moore LG, Young D, Mccullough RE, Droma T \& Zamudio S 2001a Tibetan protection from intrauterine growth restriction (IUGR) and reproductive loss at high altitude. American Journal of Human Biology 13 635-644. (https://doi.org/10.1002/ajhb.1102)

Moore LG, Zamudio S, Zhuang J, Sun S \& Droma T 2001b Oxygen transport in Tibetan women during pregnancy at 3,658 $\mathrm{m}$. American Journal of Physical Anthropology 114 42-53. (doi:10.1002/10968644(200101)114:1<42::AID-AJPA1004>3.0.CO;2-B)

Moore LG, Niermeyer S \& Vargas E 2007 Does chronic mountain sickness (CMS) have perinatal origins? Respiratory Physiology and Neurobiology 158 180-189. (https://doi.org/10.1016/j.resp.2007.06.016)

Mortola JP, Frappell PB, Aguero L \& Armstrong K 2000 Birth weight and altitude: a study in Peruvian communities. Journal of Pediatrics 136 324-329. (https://doi.org/10.1067/mpd.2000.103507)

Muttukrishna S, Suri S, Groome N \& Jauniaux E 2008 Relationships between TGFbeta proteins and oxygen concentrations inside the first trimester human gestational sac. PLOS ONE 3 e2302. (https://doi. org/10.1371/journal.pone.0002302)

Niermeyer S, Shaffer EM, Thilo E, Corbin C \& Moore LG 1993 Arterial oxygenation and pulmonary arterial pressure in healthy neonates and 
infants at high altitude. Journal of Pediatrics 123 767-772. (https://doi. org/10.1016/s0022-3476(05)80857-1)

Niermeyer S, Yang P, Shanmina, Drolkar, Zhuang J \& Moore LG 1995 Arterial oxygen saturation in Tibetan and Han infants born in Lhasa, Tibet. New England Journal of Medicine 333 1248-1252. (https://doi. org/10.1056/NEJM199511093331903)

Niermeyer S, Zamudio S \& Moore LG 2001 The people. In Adaptations to Hypoxia, pp. 43-100. Eds T Hornbein \& RB Schoene. New York, NY: Marcel Dekker and Co.

Niermeyer S, Andrade-M MP, Vargas E \& Moore LG 2015 Neonatal oxygenation, pulmonary hypertension, and evolutionary adaptation to high altitude (2013 Grover Conference series). Pulmonary Circulation 5 48-62. (https://doi.org/10.1086/679719)

Okumura A, Fuse H, Kawauchi Y, Mizuno I \& Akashi T 2003 Changes in male reproductive function after high altitude mountaineering. High Altitude Medicine and Biology 4 349-353. (https://doi. org/10.1089/152702903769192304)

Ong SS, Moore RJ, Warren AY, Crocker IP, Fulford J, Tyler DJ, Gowland PA \& Baker PN 2003 Myometrial and placental artery reactivity alone cannot explain reduced placental perfusion in pre-eclampsia and intrauterine growth restriction. BJOG 110 909-915. (https://doi.org/10.1111/j.14710528.2003.02368.x)

Osol G \& Moore LG 2014 Maternal uterine vascular remodeling during pregnancy. Microcirculation 21 38-47. (https://doi.org/10.1111/ micc.12080)

Palmer SK, Zamudio S, Coffin C, Parker S, Stamm E \& Moore LG 1992 Quantitative estimation of human uterine artery blood flow and pelvic blood flow redistribution in pregnancy. Obstetrics and Gynecology $\mathbf{8 0}$ 1000-1006.

Palmer SK, Moore LG, Young D, Cregger B, Berman JC \& Zamudio S 1999 Altered blood pressure course during normal pregnancy and increased preeclampsia at high altitude (3100 meters) in Colorado. American Journal of Obstetrics and Gynecology 180 1161-1168. (https://doi. org/10.1016/s0002-9378(99)70611-3)

Pang L, Wei Z, Li O, Huang R, Qin J, Chen H, Fan X \& Chen ZJ 2013 An increase in vascular endothelial growth factor (VEGF) and VEGF soluble receptor-1 (sFlt-1) are associated with early recurrent spontaneous abortion. PLOS ONE 8 e75759. (https://doi.org/10.1371/journal. pone.0075759)

Phipps EA, Thadhani R, Benzing T \& Karumanchi SA 2019 Pre-eclampsia: pathogenesis, novel diagnostics and therapies. Nature Reviews: Nephrology 15 275-289. (https://doi.org/10.1038/s41581-019-0119-6)

Ridder A, Giorgione V, Khalil A \& Thilaganathan B 2019 Preeclampsia: the relationship between uterine artery blood flow and trophoblast function. International Journal of Molecular Sciences 20 3263. (https:// doi.org/10.3390/ijms20133263)

Sime F, Banchero N, Penaloza D, Gamboa R, Cruz J \& Marticorena E 1963 Pulmonary hypertension in children born and living at high altitudes. American Journal of Cardiology 11 143-149. (https://doi. org/10.1016/0002-9149(63)90054-7)

Simonson TS \& Malhotra A 2020 Variability in hypoxic response: could genetics play a role? Journal of Physiology 598 1805-1806. (https://doi. org/10.1113/JP279590)
Skeffington KL, Higgins JS, Mahmoud AD, Evans AM, Sferruzzi-Perri AN, Fowden AL, Yung HW, Burton GJ, Giussani DA \& Moore LG 2016 Hypoxia, AMPK activation and uterine artery vasoreactivity. Journal of Physiology 594 1357-1369. (https://doi.org/10.1113/JP270995)

Staff AC 2019 The two-stage placental model of preeclampsia: an update. Journal of Reproductive Immunology 134-135 1-10. (https://doi. org/10.1016/j.jri.2019.07.004)

Sui GJ, Liu YH, Cheng XS, Anand IS, Harris E, Harris P \& Heath D 1988 Subacute infantile mountain sickness. Journal of Pathology 155 161-170. (https://doi.org/10.1002/path.1711550213)

Than NG, Romero R, Tarca AL, Kekesi KA, Xu Y, Xu Z, Juhasz K, Bhatti G, Leavitt RJ, Gelencser Z et al. 2018 Integrated systems biology approach identifies novel maternal and placental pathways of preeclampsia. Frontiers in Immunology 9 1661. (https://doi.org/10.3389/ fimmu.2018.01661)

Toledo-Jaldin L, Bull S, Contag S, Escudero C, Gutierrez P, Heath A, Roberts JM, Scandlyn J, Julian CG \& Moore LG 2019 Critical barriers for preeclampsia diagnosis and treatment in low-resource settings: an example from Bolivia. Pregnancy Hypertension 16 139-144. (https:// doi.org/10.1016/j.preghy.2019.03.008)

Unger C, Weiser JK, Mccullough RE, Keefe S \& Moore LG 1988 Altitude, low birth weight, and infant mortality in Colorado. JAMA 259 3427-3432. (https://doi.org/10.1001/jama.1988.03720230037027)

Vitzthum VJ 2013 Fifty fertile years: anthropologists' studies of reproduction in high altitude natives. American Journal of Human Biology 25 179-189. (https://doi.org/10.1002/ajhb.22357)

White MM, Mccullough RE, Dyckes R, Robertson AD \& Moore LG 2000 Chronic hypoxia, pregnancy, and endothelium-mediated relaxation in guinea pig uterine and thoracic arteries. American Journal of Physiology: Heart and Circulatory Physiology 278 H2069-H2075. (https://doi. org/10.1152/ajpheart.2000.278.6.H2069)

Witt KE \& Huerta-Sanchez E 2019 Convergent evolution in human and domesticate adaptation to high-altitude environments. Philosophical Transactions of the Royal Society of London: Series B, Biological Sciences 374 20180235. (https://doi.org/10.1098/rstb.2018.0235)

Zamudio S, Palmer SK, Droma T, Stamm E, Coffin C \& Moore LG 1995 Effect of altitude on uterine artery blood flow during normal pregnancy. Journal of Applied Physiology 79 7-14. (https://doi.org/10.1152/ jappl.1995.79.1.7)

Zhou D, Udpa N, Ronen R, Stobdan T, Liang J, Appenzeller O, Zhao HW, Yin Y, Du Y, Guo L et al. 2013 Whole-genome sequencing uncovers the genetic basis of chronic mountain sickness in Andean highlanders. American Journal of Human Genetics 93 452-462. (https://doi. org/10.1016/j.ajhg.2013.07.011)

Received 18 June 2020

First decision 6 August 2020

Revised Manuscript received 8 September 2020

Accepted 15 September 2020 